Departamento de Historia Universidad de Santiago de Chile

Revista de Historia Social

y de las Mentalidades

Volumen 25, $\mathrm{N}^{\circ} 1,2021: 1-28$

Issn Online: 0719-4749

\title{
¿EL TROTSKISMO TIENE ROCK? \\ DIÁLOGOS Y TENSIONES ENTRE LA MILITANCIA DE IZQUIERDA Y EL ROCK ARGENTINO COMO CONTRACULTURA (1974-1980)*
}

\author{
DOES TROTSKYSM HAVE ROCK? \\ CONTROVERSIES AND TENSIONS BETWEEN LEFTIST MILITANCY \\ AND COUNTERCULTURAL ARGENTINE ROCK (1974-1980)
}

\author{
DR. MARTIN MANGIANTINI** \\ Instituto Ravignani - CONICET \\ Buenos Aires, Argentina \\ Email: martinmangiantini@gmail.com \\ Id-ORCID: 0000-0002-4615-8693
}

\begin{abstract}
RESUMEN
El presente trabajo analizará dos publicaciones culturales editadas por el trotskismo argentino,

La Chispa y Propuesta, pensadas como un modo de acercamiento a la juventud. La primera de ellas surgió como órgano juvenil del Partido Socialista de los Trabajadores en un contexto de radicalización política hacia 1974 y 1975 y, la restante, subsidiaria de la misma organización pero sin referencia política visible, circuló en los años de la última dictadura cívico-militar. El interés del trabajo se centra en el diálogo y las tensiones entre dos esferas: la militancia de izquierda y el rock como género y expresión contracultural.
\end{abstract}

Palabras clave: Trotskismo; Rock; militancias; publicaciones culturales

\begin{abstract}
This paper will analyze two cultural publications edited by Argentine Trotskyism, La Chispa and Propuesta, thought to approach the youth. The first one emerged as a youth organ of the Socialist Workers' Party in political radicalization around 1974 and 1975 . The other one, a subsidiary of the same organization but without visible political reference, circulated during the years of the last civil-military dictatorship. The work focuses on dialogue and tensions between two areas: left-wing militancy and rock as a genre and countercultural expression.
\end{abstract}

Keywords: Trotskyism; Rock; Militancies; Cultural Publications

* $\quad$ Recibido: 7 de Octubre del 2020; Aceptado: 9 de Febrero del 2021.

** Artículo científico de producción personal. Se inscribe dentro de un proyecto posdoctoral del autor sobre el desarrollo de las izquierdas argentina durante la última dictadura militar en el país. 
Cómo citar: Mangiantini, Martín. (2021). “¿El trotskismo tiene rock? Diálogos y tensiones entre la militancia de izquierda y el rock argentino como contracultura (1974-1980)”. Revista Historia Social y de las Mentalidades, 25(1), 1-28. https://doi.org/10.35588/rhsm.v25i1.4660

\section{INTRODUCCIÓN}

Recientes aportes de la historiografía latinoamericana se preocuparon de diverso modo por analizar las características de una tríada integrada por tres elementos: la juventud, la militancia revolucionaria y las expresiones culturales no hegemónicas (también identificadas como contraculturales) en diversos países (Manzano, La era, para el caso argentino; Markarian para Uruguay; Zolov para México o Barr-Melej para Chile, entre otros).

En el caso argentino, desde mediados de los años sesenta, comenzó a manifestarse un consumo cultural ligado a la cultura beat. Tanguito, Los Gatos, Moris, Manal, Almendra y Los Abuelos de la Nada dieron el puntapié inicial a un nuevo fenómeno artístico que, en pocos años, derivó en la expresión local del género del rock. El viraje estatal represivo, junto a la puesta en práctica de una cultura autoritaria, clerical y moralista, desde la concreción del golpe de Estado de 1966, condicionó y moldeó su desarrollo. En ese escenario, determinados mensajes emanados desde este género musical se convirtieron en una voz contestataria y alternativa a la deriva política en ciernes transformándose en un embrionario desafío artístico al clima represivo. Siguiendo el insumo teórico de Markarian para el caso uruguayo, es factible identificar en la emergencia del rock argentino un naciente fenómeno contracultural entendiendo por este un conjunto de pautas inicialmente producidas y consumidas por un grupo reducido que, en el marco de la sociedad de masas y por medio de las industrias culturales y el mercado, se extendió a otras esferas de la sociedad.

Tanto en lo relativo a sus protagonistas como, centralmente, en cuanto a la composición mayoritaria de su público, la juventud fue el actor central a partir del cual el rock argentino se estructuró y desarrolló. Las letras y mensajes de su repertorio, como así también determinadas prácticas y costumbres manifestadas por quienes concurrían a este tipo de espectáculos o consumían este género, fueron caracterizadas no solo como una expresión artística más sino también como una forma de respuesta a un contexto marcado por el autoritarismo y la represión con su consecuente impronta cultural. La ofensiva gubernamental contra los estudiantes en los ámbitos universitarios y escuelas medias abonó a que el rock se gestara como una incipiente voz contestataria que encontraba una abierta y positiva recepción en amplios círculos juveniles. 
Ante esta emergencia, ciertos sectores de la militancia revolucionaria observaron este fenómeno en desarrollo. Podría argüirse que dos preocupaciones imbricadas entre sí atravesaron este interés. Por un lado, identificar si en esta expresión artística se encontraba un potencial escenario de radicalización ideológica que abonara a la construcción de un cambio político-social $\mathrm{y}$, por ende, se transformara en un fenómeno al cual la izquierda debía prestar mayor atención. Por otro, es factible suponer que las propuestas partidarias de izquierda visualizaron en este fenómeno un eventual contendiente en cuanto a la disputa por la representación de la juventud, lo que convertía al rock en un movimiento necesario de interpretar e interpelar pero, llegado el caso, desacreditar.

Historiográficamente, el diálogo entre este género musical y la militancia en Argentina se supeditó a determinadas experiencias, centralmente al derrotero de diversas organizaciones político-militares que, por disímiles razones, manifestaron un distanciamiento ante la emergencia de este fenómeno. Por ejemplo, para la principal organización armada marxista, el PRT - ERP, expresiones como el hippismo y el rock eran ejemplos de nociones pequeño-burguesas y escapistas de la realidad (Manzano, La era). La idea de "pequeño-burgués" se hallaba ligada a la elección de una vida esencialmente intelectual y con escasa praxis, o bien, a aquellas manifestaciones que alejaban al individuo del compromiso militante (como, por ejemplo, el consumo de determinados espectáculos cinematográficos o musicales ajenos a los valores militantes) (Pozzi). En otras expresiones, como aquellas ligadas a la denominada izquierda peronista, sin ignorar al rock de modo tajante, se privilegió otro tipo de géneros como el folcklore a partir de una impronta en clave nacionalista que se amoldaba mejor al proyecto político (Cataruzza) al tiempo que idiosincrasias como el hippismo eran vistas como expresiones foráneas (Manzano, La era).

El presente trabajo profundizará la exploración de los vínculos existentes en la década del setenta entre la militancia revolucionaria y el rock como contracultura en la Argentina a través del análisis de una experiencia no abordada en los estudios que versaron sobre estos tópicos: el discurso público y los proyectos editoriales del Partido Socialista de los Trabajadores (en adelante, PST). En contraposición a la abundante bibliografía que versó sobre las nociones y prácticas de las organizaciones político-militares, el PST se inscribe dentro de una propuesta subsidiaria del campo teórico del trotskismo, una de las diversas expresiones del amplio arco de experiencias autodefinidas como revolucionarias que actuaron en el agitado contexto de los años setenta. ${ }^{1}$

1 Representada por la figura de Nahuel Moreno, esta trayectoria política se originó en los años cuarenta con la formación del GOM (Grupo Obrero Marxista), luego rebautizado POR (Partido 
Para la realización del trabajo se utilizarán como fuentes centrales dos insumos editoriales no analizados por aquella producción que indagó los puentes entre la militancia y el rock. Se trata de publicaciones cronológicamente consecutivas pero disímiles entre sí, las revistas La Chispa (editada en el bienio 1974-1975) y Propuesta (proyecto editorial de circulación en los años de la dictadura cívico-militar que publicó su primer número en junio de 1977). Ambas iniciativas compartieron la aspiración de dirigirse a un público juvenil pero los objetivos, características y contextos políticos respectivos en los que se desarrolló cada una de ellas, las convirtió en producciones con rasgos y perspectivas notoriamente distantes entre sí.

A partir de estos insumos, el presente artículo indagará la relación, el diálogo y el análisis que, desde la militancia revolucionaria, se sostuvo con respecto a la experiencia del rock local con el objeto de reflexionar el modo y las diferencias mediante las cuales ambas esferas visualizaban y pensaban a la juventud como sujeto social y político. La hipótesis que guía este trabajo sostiene que, en la mirada de la militancia trotskista argentina, la emergencia del rock local como expresión artística contestataria fue un fenómeno posible de ser explorado y pensado a la luz de su factibilidad como parte de un proyecto político radical. Por ello, fueron inherentes a estas inquietudes los deseos de explorar si se trataba de una expresión de rebeldía juvenil embrionariamente antisistémica $\mathrm{y}$, a su vez, si sus protagonistas eran sujetos posibles de incluir en un proceso de transformación política profunda o, por el contrario, si vislumbraban una deriva tendiente a recaer en las lógicas del mercado y mantener el statu quo. A raíz de la evidencia que se presentará, se sostiene que, aunque atento y abierto a esa exploración, el trotskismo acabó por primar una visión del fenómeno del rock que identificó la necesidad de disputar con este los valores desarrollados hacia la juventud y, en razón de ello, prevaleció finalmente una lógica impugnatoria o dicotómica que, a diferencia de ciertas visiones historiográficas esgrimidas,

Obrero Revolucionario). En los cincuenta, esta corriente formó parte del (PSRN) Partido Socialista de la Revolución Nacional y, tras la caída de Perón, practicó la táctica del "entrismo" en el movimiento obrero peronista a través de la publicación Palabra Obrera. En 1965 con el FRIP (Frente Revolucionario Indoamericanista Popular) dirigido por los hermanos Santucho, unión de la que nació el Partido Revolucionario de los Trabajadores (PRT). Tras un proceso de debate interno, en 1968, esta organización se dividió en dos grupos diferenciados: la corriente "morenista" dio forma al denominado PRT - La Verdad que actuó hasta 1972, año en que se fusionó con un desprendimiento del Partido Socialista Argentino (dirigido por Juan Carlos Coral) y dio origen al PST, objeto de estudio de este trabajo. Con esta denominación el "morenismo" actuó (de manera legal y clandestina, respectivamente) hasta la finalización de la dictadura en 1983 para convertirse en el Movimiento al Socialismo. 
impidió una confluencia entre ambas esferas en toda esta etapa. No obstante, como se verá, también es posible aseverar que las razones de diferenciación y desacuerdo que llevaron al trotskismo argentino a polemizar con el rock no fueron necesariamente similares a aquellas que otras expresiones de la izquierda (tales como las organizaciones político-militares o la izquierda peronista) esgrimieron como motivaciones para hacerlo.

\section{LA CHISPA, ENTRE LA RADICALIZACIÓN Y LA REPRESIÓN (1974-1975)}

La revista La Chispa fue impulsada en 1974 por el ala juvenil del PST, la denominada Juventud Socialista de Avanzada (en adelante, JSA), experiencia que conlleva un rasgo de interés. El lanzamiento de la JSA fue una apuesta de este partido al proponerse desarrollar una organización paralela que, a la vez, poseyera cierta autonomía con relación al aparato partidario con el objetivo de nuclear a la militancia juvenil cercana pero no necesariamente más activa o comprometida.

Esta política se relacionó con dos elementos simultáneos. En primer lugar, partió de una caracterización que, si bien destacó el papel protagonizado por la juventud en diversos procesos de conflictividad, a la vez encontró como limitación su carácter más volátil e inestable al tratarse de un actor no inserto en forma directa en el proceso productivo y cuyas luchas, a diferencia del movimiento obrero, no afectaban directamente sus condiciones de subsistencia (Mangiantini, Itinerarios y "Nociones"). Para la dirección del PST, este fenómeno generaba diversos interrogantes: ¿cómo incorporar a la organización a numerosos sectores juveniles cercanos sin que ello implicara una alteración de las normativas de disciplina interna? Dialécticamente, ¿cómo evitar que esa disciplina y las exigencias de la militancia no redundaran en un alejamiento de los jóvenes interesados en participar con grados de compromiso disímil?

La creación de la JSA se presentó como la posibilidad de conformar un organismo juvenil autónomo $\mathrm{y}$, a la vez, vinculado al partido entendiendo por ello la capacidad de tomar resoluciones, contar con finanzas propias, locales y publicaciones particulares ("El rol de la JSA" 1; "Una JS autónoma" 12). Puede afirmarse que, en la práctica, las fronteras entre la JSA y la entidad partidaria fueron, por momentos, difusas. Por ejemplo, diversos cuadros del PST fueron, simultáneamente, parte de la conducción de la JSA y, dialécticamente, diversos representantes de esta juventud se integraron a los organismos de dirección partidaria ("Documento estudiantil" 2).

Como parte de esta experiencia, en abril de 1974, la JSA editó su órgano de prensa particular, La Chispa, independiente y en simultáneo al periódico semanal 
que impulsaba el PST en estos años, Avanzada Socialista. Se publicaron once números a lo largo de ese año y cinco ediciones el año siguiente. En agosto de 1975, se lanzó el número 16 que, sin saberlo previamente ni anunciarse, se trataría de su último ejemplar. Los ataques y atentados por parte de grupos paraestatales contra el PST obligaron a una lógica de repliegue y semiclandestinidad que implicó reducir al mínimo el número de actividades expuestas. Ello llevó a una finalización de este tipo de propuestas editoriales como así también de las actividades más públicas de la organización (Mangiantini, Itinerarios).

A lo largo de dieciséis números se sucedieron diversos artículos factibles de clasificar de acuerdo a tres grandes subgrupos. Por un lado, escritos de una índole similar a los editados en el periódico regular (pertinentes a la coyuntura nacional e internacional, conflictos obreros, o bien, de debate táctico con otras corrientes revolucionarias). En segundo orden, fueron frecuentes los artículos referidos a la realidad de las universidades, colegios y al movimiento estudiantil en general. Por último, se alternan diversas reflexiones alrededor de problemáticas pertinentes a la juventud, dentro de las cuales aparecen referencias hacia el rock nacional como propuesta cultural. Si se pondera en términos cuantitativos el lugar que esta publicación juvenil brindó al rock local como fenómeno, los datos revelan que, sobre un total de dieciséis números, en siete de ellos, esta expresión tuvo su espacio a través de nueve artículos diferentes. Se trató entonces de un fenómeno que interesó a la organización hallándose presente dentro de un abanico de intereses más amplio, sin que la temática ocupara el centro de las inquietudes.

A mediados de 1974, La Chispa realizó un primer balance acabado sobre la deriva del rock argentino desde sus orígenes. La revista percibió una evolución en la retórica emanada por este género a lo largo de siete años de vida en sintonía con los cambios que la juventud experimentaba tanto a nivel nacional como mundial. En este sentido, fenómenos como el componente juvenil en las protestas de París o Praga, sumado a los conflictos que, en Argentina, habían tenido a esta generación como protagonista (por ejemplo, las acciones contra las medidas disciplinarias en las escuelas, las luchas por la derogación de exámenes de ingreso y materias filtro en la universidad y, desde ya, el protagonismo de la juventud trabajadora en el movimiento obrero) fueron factores que, para esta publicación, colaboraron en una mutación del discurso del rock.

Según se analizó, el rock argentino atravesó tres etapas diversas. Su surgimiento, hacia 1967, se presentó como una respuesta juvenil al clima autoritario imperante pero, al mismo tiempo, las letras daban cuenta de dos aspectos primordiales. Por un lado, cierta denuncia a aquellos valores establecidos a partir de la riqueza y el status (por ejemplo, en "El rey lloró", Los Gatos 
narraban un diálogo entre un campesino y un rey económicamente poderoso pero descontento que le pedía, fallidamente, al primero un modo de alcanzar la felicidad a cambio de bienes). Por otro lado, existía un abanico de canciones que expresaban sensaciones de angustia, soledad, frustración y desengaño por parte de los jóvenes. En el marco de una letra con tintes románticos, "Ayer nomás" (grabada tanto por Los Gatos como por Moris con ciertas diferencias) mostraba un país con falta de libertad, ausencia de expectativas y pobreza económica (Gerardo 10-11).

Estas sensaciones simbolizaban también la oposición juvenil al futuro propuesto. La canción "Yo vivo en una ciudad", del grupo Pedro y Pablo, representaba a la figura de un oficinista, prototípico del mundo urbano e impregnado de monotonía y rutinas. El oficinista también reproducía la imagen de una clase media individualista, conservadora, preocupada por el consumismo y moralista. Esa "pequeña-burguesía", obsesionada con el deber ser y las apariencias, sostenía valores que se trasladaban no solo al ámbito laboral sino también al espacio familiar y a las relaciones sexo-afectivas. Por ello, según determinados estudios, el rock nacional expresó también una ruptura generacional y una brecha entre los hijos que no deseaban un futuro similar al de sus progenitores (Manzano, La era). Se trató de la emergencia de una generación que proyectó un estilo de vida laboral, familiar y afectivo diverso al institucionalizado y, en definitiva, simbolizado en la moral occidental y cristiana emanada desde el propio aparato estatal.

Este tipo de imaginario se hallaba en diálogo con organizaciones como el PST. Si bien, para ella, el término "pequeño-burgués" era peyorativo y se anclaba mayormente a la noción de una idiosincrasia que primaba la labor intelectual y el desarrollo individual por sobre el compromiso político, también era una categoría que servía para definir a la estructura familiar y el entorno social. En diversos materiales de circulación interna dentro de la organización, el núcleo familiar de un militante apareció como una tensión que, en ocasiones, podía obstaculizar o limitar un normal desempeño de su actividad y compromiso militante (Mangiantini, Nociones). En este terreno, el trotskismo y el rock local compartían determinadas concepciones en torno al modo en el que los lazos familiares podrían inhibir el desarrollo político-personal.

La Chispa identificó que, en 1969, el rock nacional dio luz a una segunda camada de autores como Javier Martínez, Pajarito Zaguri, Luis Alberto Spinetta y la continuidad de Moris. Para la revista, se trató de un salto en el género con la incorporación de un tono de denuncia violento y contestatario desde diversos planos: el llamado a la protesta de modo directo en canciones como "Alza la voz" de Pajarito Zaguri y, sobre todo, "La marcha de la bronca" del dúo Pedro y 
Pablo; el cuestionamiento a las pautas culturales y normativas sociales existentes en grupos como Manal y temas como "No pibe" o "Para ser un hombre más"; la denuncia más encubierta en estrofas de Litto Nebbia como "Reflexiones de un hombre singular" (Camina por la calle, y dime si no sientes, que alguien te persigue, y te hace sentir mal); o la aparición del grupo Almendra manifestando una poética crítica a la enajenación en letras como "A estos hombres tristes" o "Fermín" (Gerardo 10-11).

La inquietud alrededor de la hipotética radicalización ideológica del rock y el interrogante sobre la posibilidad de encontrar puentes con la militancia revolucionaria, se hizo evidente cada vez que un solista o conjunto accedía a una entrevista. Así, a mediados de 1974, La Chispa interrogó sobre esta posible radicalización a Moris, quien respondió por la positiva argumentando que el artista se hallaba ligado a los problemas del país y el mundo en el que vivía y, a la vez, experimentaba un proceso intelectual que le brindaba mayor conciencia política y social ("Moris: pionero del rock" 11). En la misma línea, en un reportaje realizado al grupo Sui Generis, se consultó a sus miembros a qué atribuían el mayor contenido crítico hacia el sistema capitalista en las letras de rock más recientes, a lo que su cantante, Nito Mestre, respondió que, en la medida en que los jóvenes querían cambiar la sociedad, las canciones se transformaban en un reflejo de ello. Como corolario del intento por profundizar más aún la reflexión sobre sus objetivos políticos, La Chispa repreguntó sobre la utilidad de la música del grupo, a lo que Charly García, en clara sintonía con la publicación, respondió que, idealmente, le gustaría que su música ayudara a un proceso revolucionario o, por lo menos, a que el público profundizara sus críticas al sistema. Resulta interesante como ejemplificación de la tensión latente entre una publicación subsidiaria de una vertiente revolucionaria y el mundo artístico que, para finalizar la entrevista, La Chispa dejó abierta la posibilidad a los músicos de agregar libremente aquello que quisieran expresar, a lo que Charly García, con evidente conocimiento del público al que se dirigía, respondió:

(...) Yo pienso que hay muchos militantes que tienen prejuicio con el rock. Su actividad política los lleva a pensar que el rock es reaccionario, que no sirve y que no ayuda. Y yo digo que no es así. (...) Que hay un rock que, es cierto, es reaccionario y que solo sirve para hacer escapar a la gente de la realidad. Pero hay otro rock, que por su música, su contenido, su técnica, se va desarrollando al compás de todo un proceso de cambio, un rock que quiere servir, de la mejor manera posible, a ese cambio. Ese es nuestro rock ("Reportaje a Sui Generis" 14-15). 
Finalmente, La Chispa visualizó un quiebre para el rock local en 1971 con la separación de una importante cantidad de grupos. Desde su óptica, salvo excepciones como, por ejemplo, las derivas de Spinetta hacia una retórica vislumbrada como surrealista, se trató de un momento en el que el rock, como representación de la juventud, identificó con mayor claridad que el capitalismo era el enemigo central. Así, visualizó en determinados solistas una continuidad musical con Pedro y Pablo como voceros de las denuncias. Por ejemplo, en "Hombres de hierro", Gieco alertaba sobre la represión en el Mendozazo y en "Ámame nena", Porchetto abogaba directamente por la eliminación de la ideología fascista, el reparto de los latifundios, el fin del hambre y la muerte del presidente estadounidense Nixon. También identificó expresiones de este compromiso en grupos como Aquelarre quien, en "Aves rapaces", denunciaba a la dictadura militar chilena, y en artistas provenientes de anteriores etapas como el propio Nebbia o Moris. Este último, en una versión aún más radicalizada denunciaba la opresión al trabajador en "Muchacho del taller y la oficina" o las condiciones precarias de vivienda ("Las villas de emergencia"). En sintonía, La Chispa también identificó mensajes de denuncia más sutiles hacia el sistema. Por ejemplo, Sui Generis, mediante personajes como "Natalio Ruíz", daba cuenta de hombres alienados e infelices cumpliendo con prerrogativas sociales (Gerardo 10-11).

La posterior apertura democrática que desembocó en las elecciones presidenciales de 1973 terminó de consolidar este movimiento cultural. Los recitales y encuentros musicales se transformaron en ámbitos de reunión y expresión de una juventud que, a la vez, se convertía en protagonista central de las derivas políticas del país. El rápido retorno a un contexto represivo desde finales de ese año en el que primó la ofensiva contra el activismo obrero y juvenil por parte de organizaciones paraestatales de derecha, como la Triple A, actuando bajo el amparo del propio aparato gubernamental, dio lugar a un contexto más álgido que condicionó las acciones y orientaciones por parte de las organizaciones y la militancia (Franco; Bufano y Teixidó).

Como deriva de este escenario, los análisis se radicalizaron volviéndose también dicotómicos y con ausencia de matices. En un nuevo balance que La Chispa realizó sobre el fenómeno del rock local en agosto de 1975, estableció una división tajante entre aquellas manifestaciones artísticas que se mantenían indemnes al "afán comercial” (como Sui Generis², Gieco, Arco Iris, Pedro y Pablo, Nebbia o Moris) de aquellos que protagonizaron un "desvío" en el género. Así, se identificó en el rock un

2 El caso de Sui Generis es interesante porque, para ciertos sectores del propio rock local (sobre todo de la primera camada) se trató de un proyecto de carácter complaciente, lo cual contrasta con la mirada esgrimida por La Chispa. 
camino alternativo al compromiso político, adjetivado como "surrealista" y "snob", caracterizado por letras que carecían de un sentido concreto transformándose en inaccesibles al oído popular. En este terreno, se incluía la deriva de Spinetta con Invisible, el grupo Color Humano o nuevos conjuntos como Ave Rock (Beto Pelay de La Plata 28). Se desprende del análisis una marcada grieta en la que el arte se hallaba ante dos opciones: o ponerse al servicio de la lucha contra la opresión en favor de un cambio político-social, o bien, optar por una deriva comercial vacía de contenido más allá de refugiarse en pretensiosas construcciones poético-literarias que, en la práctica, resultaban inocuas.

Este escenario dicotómico llevó a La Chispa a polemizar con otras revistas que también tenían como temática central al rock y como público destinatario a la juventud, como fue el caso de Pelo. Así, en su décimo número, dedicó una carta abierta a esta publicación a modo de interpelación cuestionando la ausencia de denuncias al sistema; su omisión de cómo el arte (y, puntualmente el rock) era condicionado por este; el silencio ante las desigualdades imperantes en el mundo musical entre quienes tenían la posibilidad de acceder a compañías discográficas y a la difusión de sus materiales vía radial y quienes no; la crítica a la supuesta neutralidad de las expresiones artísticas, entre otros tópicos. A modo de cierre, se exhortaba a Pelo "(...) como vocero de un importante grupo de la juventud, que denuncie todos estos problemas, para demostrar que asume su compromiso con el rock y con todos los que formamos parte de él" (Celiz 23). Esta interpelación no era aislada, sino un reflejo de caracterizaciones cruzadas y exigencias de definiciones políticas más claras entre el ambiente del rock como expresión contracultural y la militancia revolucionaria orgánica. Por ejemplo, en estos años, el periodista y poeta Miguel Grinberg en la revista Eco Contemporáneo utilizó la categoría de "mufados" para definir a aquella juventud descontenta y refractaria a la cultura del mercado y el consumo pero, a la vez, ajena a la militancia política (Manzano, La era). Así, se daba cuenta de un camino intermedio que, en discursos como el de La Chispa, no se visualizaba como una alternativa plausible pero que, a su vez, era objeto de disputa.

De estos artículos se desprendía como una preocupación la posibilidad de que un proyecto contestatario como el rock fuera subsumido dentro de una lógica comercial y empresarial. Como argumentó Pujol ("Rebeldes"), resultaba dificultoso resolver determinadas contradicciones toda vez que, por ejemplo, la posibilidad de editar un disco recaía en la vinculación del artista con únicamente dos o tres compañías comerciales, siendo engorroso realizar cualquier tipo de iniciativa independiente. Estas contradicciones resultan claras en el modo explícito de interrogar a los músicos por parte de La Chispa. En el reportaje a Moris antes mencionado, sin matices, la revista le consultó: "¿Pretendés algo 
con lo que hacés o simplemente lo hacés por dinero?" y, unas semanas después, en un encuentro con Gieco, se lo interpeló sobre los motivos por los cuales no se refería en sus declaraciones a las dificultades de la mayoría de los jóvenes rockeros para grabar y "poder llegar". Esta retórica generaba respuestas no carentes de incomodidad por parte de los artistas ("Moris" 11; "León Gieco: época" 23). Como contraparte, se destacaban acciones como, por ejemplo, la presencia de diversos músicos en un festival en la Facultad de Derecho organizado por la juventud del PST con el fin de recaudar fondos por la destrucción de un local partidario tras un allanamiento policial, subrayando que los invitados (Moris y Sui Generis) únicamente cobraron los gastos de transporte de equipos ("Rock en Derecho" 13).

Resulta llamativo que la deriva comercial del rock emergiera como una preocupación más sistemática en artículos o reportajes que el énfasis en el contexto de persecución política y violencia parapolicial que, a su vez, tenía un correlato estatal con un incremento de la censura y el control del arte y los medios de comunicación, exacerbado desde el ascenso de María Estela Martínez de Perón a la presidencia. De hecho, la problemática de la censura únicamente apareció con claridad en un reportaje a Sui Generis a raíz de la prohibición de un festival en apoyo al sindicato automotriz SMATA de Córdoba, en la Federación de Box de Buenos Aires del que la banda formaría parte ("Reportaje a Sui Generis" 14-15).

En conclusión, esta corriente no ignoró ni menospreció la emergencia del rock local como expresión artística a la vez que política, centralmente dada la atracción que ella generaba en una camada amplia de jóvenes, siendo este un sujeto factible de ser asimilado a un proyecto revolucionario. Es posible aseverar que los primeros momentos de la retórica trotskista fueron marcados por un prisma de empatía con respecto al fenómeno musical en desarrollo. Los cuestionamientos tanto a la política represiva como a los valores morales esgrimidos a nivel gubernamental y el rechazo al devenir económico, social e incluso familiar que le deparaba a la juventud, fueron tópicos que permitieron a la militancia revolucionaria vislumbrar un nexo con sus propios ideales y objetivos y establecer puentes de comunicación en la perspectiva de confluir con su respectiva base de apoyo. No obstante, la cada vez más álgida represión, el incremento de la violencia política y el paso cada vez más necesario por parte de las organizaciones revolucionarias hacia lógicas de clandestinidad, revirtieron los análisis hacia caminos excluyentes en el que la política militante comenzó a exigirle a las expresiones culturales definiciones claras y tajantes sin lugar para matices. Ello llevó a La Chispa a interpelar cada vez más álgidamente a los protagonistas del rock en torno a la utilidad revolucionaria de su arte y a 
subrayar la necesidad de no recaer en lógicas comerciales y empresariales afines a un sistema a derribar. Como se verá, el golpe de Estado acaecido en marzo de 1976 bifurcaría más aún los puntos de encuentro en el marco de una coyuntura represiva que, aunque de diverso modo, afectó a ambas expresiones.

\section{EL ROCK Y LA MILITANCIA ENTRE DROGAS, HIPPISMO, FEMINISMOS Y REVISIONES SEXO-AFECTIVAS}

Vinculado al anterior apartado, hay dos temáticas que, aunque colaterales, permiten reflexionar sobre los lazos y las tensiones existentes entre el rock nacional y la militancia revolucionaria en cuanto a esferas disímiles de representación de la juventud. En primer lugar, en el imaginario general, existía una vinculación directa entre tres elementos: el rock, el hippismo y el consumo de drogas. Como estudió Manzano ("Política"), desde la segunda mitad del siglo XX, para el aparato estatal, la figura del toxicómano se encontró más asociada a la juventud que a otro tipo de sujetos. El consumo de marihuana y de anfetaminas fue inherente a experiencias contraculturales o de la sociabilidad ligada al rock pero, claramente, excedió a estas y se amplió a diversos círculos socioculturales. En este aspecto, la brecha discursiva entre el rock y la militancia de izquierda se hizo notoria. En contraposición al consumo de drogas, la izquierda argentina se posicionó en las antípodas de esta práctica basándose en justificaciones de índole ideológicas. El PST, en sintonía con ello, sostuvo que la droga era una resultante del sistema capitalista por tratarse de un negocio rentable pero, a su vez, porque su consumo resultaba funcional a ese sistema al "apartarse del mundo a partir de los narcóticos, crear su propio mundo de sueños y suicidarse lentamente (...)" (Marcelo 11). En relación con ello, afirmaba desde su voz juvenil: "A la burguesía le conviene tener miles de jóvenes narcotizados y escuchando música y no haciendo manifestaciones y luchando contra los gobiernos patronales y el imperialismo" (Marcelo 11). Como se desprende, se identificó a la droga y a la música (en ocasiones, vinculadas ambas al hippismo) como dos esferas nocivas que les permitía a la juventud evadirse de su entorno sin confrontar con este ni pugnar por su cambio. Se evidencia que este tópico fue una preocupación dentro de la esfera militante a tal punto que la temática se trató no solo en su publicación juvenil sino también en su semanario partidario ("Hijos vs. Padres" 11).

En segundo orden, otra temática vinculada a la subcultura del rock recayó en la construcción de relaciones sexo-afectivas de nuevo tipo. Es factible aseverar que, en el caso de esta corriente, los acuerdos y tensiones con las pautas culturales emanadas del rock local fueron directamente antagónicas en 
perspectiva comparativa con las restantes expresiones del campo de las izquierdas (específicamente, los casos del PRT - ERP y de la izquierda peronista). En retroalimentación con la idiosincrasia del hippismo, el rock local tuvo como uno de sus rasgos la defensa de relaciones sexo-afectivas entre los jóvenes, enmarcadas en una mayor libertad y por fuera de los mandatos monogámicos de sus progenitores (Pujol, "Rebeldes"). A diferencia de organizaciones aferradas a valores monogámicos, en el caso del PST, se extendió al interior del partido una revisión de la idea de pareja y una recepción a la diversidad de las relaciones humanas con el consecuente cuestionamiento a la monogamia como un valor en sí y a la noción de la familia tradicional, definida como una institución útil a la reproducción del sistema de dominación burgués (Mangiantini y Trebisacce).

En sus análisis particulares sobre la juventud, esta corriente caracterizó a la familia como parte de las relaciones de propiedad y de la división de tareas lo que, a la vez, se congeniaba con el sistema patriarcal y la moral religiosa de la virginidad en la mujer. No obstante, se analizaba que el avance del capitalismo y de la sociedad de masas hizo de la mujer un objeto sexual de consumo por lo que caracterizaban a la familia monógama y a la mujer-mercancía como las dos caras de una misma moral a revertir ("Sexo: ¿tabú o liberación?" 14-15). La sistemática oposición del PST, en 1974, al decreto de prohibición de venta de anticonceptivos lanzado por el gobierno de María Estela Martínez de Perón fue un eje a partir del cual este partido profundizó sus percepciones alrededor de la estructura familiar ("Más hijos" 6; "La ley de los anticonceptivos" 4). Ello tuvo también su expresión en los intercambios que los miembros de La Chispa realizaron con los músicos a quienes se les consultó su opinión acerca de los lazos de pareja ("Reportaje a Sui Generis" 14-15).

Sin embargo, más allá de la negación por la monogamia y la familia tradicional, Manzano (La era) encontró en el rock nacional rasgos impregnados de nociones de masculinidad en el marco de una política cultural que prácticamente invisibilizó el protagonismo de las mujeres. Las rutinas y prácticas del público rockero obstaculizaron la plena integración femenina lo que también se reflejó en el protagonismo de las artistas. La ausencia de mujeres en el escenario o en las discográficas se contrapesó, a su vez, con una fuerte presencia en las letras de las canciones a través de dos vías de representación de lo femenino: como símbolos de amor y ternura (incluso frívola) expresado en letras como "Muchacha ojos de papel" de Almendra o "Catalina Bahía" de Pedro y Pablo; o bien, como meros objetos de deseo sexual (por ejemplo, "Me gusta ese tajo" de Pescado Rabioso). Así, tomando como base de su análisis a organizaciones como el PRT-ERP o Montoneros, Manzano ( $L a$ era) esgrimió que, en sus mutuas confrontaciones simbólicas, el rock y las organizaciones revolucionarias 
compitieron por interpelar centralmente a los varones jóvenes sin diferenciarse en cuanto al registro.

Resulta de interés establecer un matiz en el caso de la experiencia trotskista analizada en este artículo. Una temática que el PST ponderó en los años setenta consistió en la reivindicación en torno a la llamada "liberación de la mujer" (Mangiantini y Trebisacce). Las diversas publicaciones partidarias expresaron su interés por visibilizar la situación de doble explotación que padecían las mujeres en tanto trabajadoras y amas de casa, pero simultánea y enfáticamente, denunciando el papel jugado por los medios de comunicación, la publicidad, la familia y la escuela en la reproducción de un estereotipo femenino pasivo y objeto del placer masculino ("La mujer" 4; "Mujeres en lucha" 10). Se trató de una línea teórico-discursiva excepcional dentro de las izquierdas del período y, a la vez, en perspectiva comparativa, ajena a una contracultura del rock, al ubicar a la mujer en un papel divergente al pugnar por una ruptura de sus relaciones de opresión.

Para Manzano ( $L$ a era), la postura anti-femenina de ciertos rockeros no implicó solamente un machismo internalizado sino también un modo de contrarrestar a las permanentes acusaciones homofóbicas que se indilgaban a la cultura del rock a partir de la vestimenta o el uso del pelo largo. En ese sentido, se construyó un fantasma homosexual en torno a los rockeros, visto como un desafío a la continuidad del patriarcado, que fue respondido por sus acusados mediante la reproducción de proclamas machistas. La autora sostuvo que, al igual que el rock, los emergentes movimientos de las mujeres y los homosexuales no eran legitimados por la izquierda revolucionaria en la medida que conferían sentidos individuales o culturales a la idea de liberación. Efectivamente, desde el campo de las izquierdas, el rechazo a la homosexualidad tuvo otras motivaciones. En los regímenes del llamado socialismo real, fue considerada un peligro social bajo el argumento de tratarse de un producto de contenido burgués y fascista identificando a la homosexualidad con diversos tipos de desviaciones ajenas a la vida cotidiana del proletariado (Goldman).

No obstante, vale aquí también establecer un matiz en la propuesta estudiada en cuanto al bagaje teórico esgrimido en perspectiva comparativa tanto con las diversas expresiones de las izquierdas como con la retórica del rock. La defensa a las orientaciones sexuales disidentes se desarrolló a través de la relación forjada entre esta corriente y el Frente de Liberación Homosexual (FLH) mediante la realización de campañas conjuntas por diversas temáticas como la derogación del decreto que prohibía la información y difusión de métodos anticonceptivos y la utilización del local central del PST para la realización de las reuniones del Grupo de Política Sexual, en las que se esbozó 
una confluencia entre la militancia feminista y la homosexual (Mangiantini, Itinerarios; Simonetto). Como conclusión parcial, es factible aseverar que, si bien estas iniciativas no se hallaron carentes de tensiones internas, permiten reflexionar en torno a los encuentros y desencuentros entre la militancia de izquierda y el rock local de un modo no monolítico sino matizado de acuerdo a cada corriente en particular. En este sentido, es posible considerar al objeto de estudio aquí presentado no solo con determinados aspectos idiosincráticos y programáticos divergentes a la cultura propuesta por el rock local, sino también en relación con diversas expresiones contemporáneas que formaban parte del amplio arco de la llamada izquierda revolucionaria.

\section{PROPUESTA, RESISTENCIA SUBTERRÁNEA AL TERROR (1977-1980)}

La revista Propuesta, por su parte, fue un proyecto editorial cultural subterráneo en el contexto dictatorial. Inicialmente lanzada como empresa independiente por un grupo de jóvenes de la localidad bonaerense de Quilmes, acabó por convertirse en una publicación vinculada al PST sin que mediara indicio público alguno distinguible de esa relación. En ese sentido, Propuesta no puede ser caracterizada como una de las variadas revistas partidarias clandestinas que circularon durante los años de la dictadura cívico-militar, pero tampoco como una empresa comercial tradicional. Se trató de un proyecto cultural que tuvo por objetivo dirigirse a un amplio público juvenil, a través de una retórica política soslayada y que, siendo estimulada por un partido, se desarrolló en términos laxos con la dirección de esa organización sin ser necesariamente un vocero de esta. Por ello, no puede ser considerada una continuidad directa de La Chispa más allá de dirigirse a un público similar sino más bien, una alternativa editorial de nuevo tipo con una dinámica legal en un contexto de clandestinidad.

A lo largo de 1977 fueron publicados cinco números con una regularidad prácticamente mensual. Si bien en ese colectivo participaban militantes del PST, fue al año siguiente que el proyecto se vinculó fehacientemente con el partido y trasladó su lugar de redacción a la Capital Federal. Cuando, en abril de ese año, salió a la luz el número 6 de la revista, la injerencia del partido en la publicación ya era concreta lo que determinó una cierta renovación y modificación de su equipo editorial acorde a los intereses de la organización. Con una periodicidad prácticamente mensual, Propuesta se sostuvo con veintidós números en total hasta su finalización en enero de 1980.

El PST contó con un equipo partidario dedicado a esta tarea (integrado por los militantes Roberto Catania, "Lito" y Silvio Winderbaum, entre otros) 
que, en los hechos, acabó por gozar de cierta autonomía con relación a la política partidaria general ("Documento de orientación del Frente R.J."). No obstante, dicho equipo tenía la supervisión de un miembro de la dirección nacional del partido (apodado El Mujik) que, si bien no intervenía en el contenido de la publicación, estaba atento a su difusión, finanzas y distribución. Al tratarse de un espacio de superficie del PST, los militantes de este partido que se integraban a Propuesta se escindían de otro tipo de actividad orgánica y se dedicaban exclusivamente a esa tarea, ajenos a las restantes actividades que se desarrollaban en la clandestinidad ("Entrevista a Silvio Winderbaum").

Si bien el objetivo inicial de esta publicación fue subdividir su contenido en aspectos políticos (matizados dada la coyuntura represiva), ideológicos (mediante la crítica a los valores y pautas culturales emanadas del propio sistema) y artísticos, en la práctica esta última esfera fue la más destacada. Por ello, comparativamente con La Chispa, Propuesta brindó un notable espacio al rock local como fenómeno. Entre su sexta y su vigesimosegunda edición (números en los que la revista se hallaba directamente vinculada al PST) se registra una veintena de artículos y reportajes exclusivamente dedicados al fenómeno del rock, a lo que se suman diversos comentarios breves sobre flamantes discos o recitales realizados. Incluso, la temática se reflejó como un tópico (central o parcial) de su tapa en ocho oportunidades sobre el total de dieciséis números editados en este período. Podría argumentarse que, comparativamente con La Chispa, se trató de un interés creciente por analizar al rock y sus derivas, pero también es factible de sostener, que la represión álgida del período permitía un menor desarrollo de artículos directamente políticos y que el formato de la publicación conllevaba una presentación netamente cultural, además de estar específicamente dirigida a la juventud. ${ }^{3}$

La mayor presencia del rock nacional en los análisis sobre las experiencias culturales realizadas en el período dictatorial puede obedecer a diversas circunstancias. En primer lugar, lejos de disminuir, los conciertos de rock se convirtieron en uno de los pocos espacios posibles de participación amplia, sobre todo desde el año 1979. En un marco de restricciones y represión, los conciertos se transformaron en un ámbito de sociabilidad antagónico a la realidad (Pujol, Rock). Diversos análisis indican que el vacío de representatividad y el desmantelamiento de las agrupaciones políticas permitieron al rock canalizar gran parte de la constitución de las identidades Cuadernos del camino. En sus cinco números editados, no existe ninguna referencia al rock nacional como género. De hecho, la música tiene un espacio absolutamente minoritario y las escasas referencias que versan sobre ella refieren a otros géneros. 
juveniles (Vila, "Rock"; Alabarces; Díaz). La masividad lograda por este género en el contexto dictatorial habilitó una discusión historiográfica subsidiaria en torno a si esta expresión artística revertía, a su vez, era una manifestación de resistencia y respuesta cultural al marco represivo impuesto desde el Estado. El pionero trabajo de Vila analizó como, mediante metáforas y alegorías, el rock se convirtió en uno de los escasos opositores al régimen militar (o, al menos, en un modo de refugio) (Vila, "Argentina's"). Esta hipótesis mantuvo una notoria adhesión en diversas producciones posteriores (Pujol, Rock; Favoretto). Por el contrario, otros trabajos dieron cuenta que, para el sector empresarial, el público del rock constituyó un sector claramente diferenciado de la militancia política y, como tal, lucrativo. A la vez, los ideales pacifistas asociados al género permitían dar forma a un imaginario de juventud alternativo al enemigo construido por el Estado en ese momento, más despolitizado y desinteresado por lograr un cambio social. Por ello, lejos de ser visto como un peligro, la realización de un concierto de rock podría ser presentada como una instancia de reunificación y pacificación nacional despolitizada (Di Cione).

Vinculado a ello, los números de Propuesta presentan una constante preocupación, mediante sus artículos y reportajes, por identificar en qué registro se hallaba el rock local comparativamente con el período previo a la dictadura. Dado el contexto, los análisis se encontraron con un tono marcado por la minimización de la esfera política y la preponderancia por los aspectos artísticos y estilísticos. Así, la revista identificó el año 1977 como un quiebre para el rock dada la separación de determinados grupos (como La Máquina de hacer pájaros o Arco Iris) y la salida del país de distintos artistas, como Gieco, Moris o Nebbia (Grinberg 6-8; Winderbaum, "Vuelve el rock" 2425). En este escenario, el periodista Miguel Grinberg aseveró, en un tono más politizado, que el rock había sobrevivido a la partida de artistas de todos los géneros en un contexto de vaciamiento del espíritu creador. Pero, pese a ello, el género se hallaba golpeado por diversos motivos tales como el ego o el afán comercial y de lucro. Ante ello, instaba a la música, como último baluarte de la conciencia juvenil, a ser un arma contra las verdades inmutables (Grinberg 6-8).

De modo más o menos directo, la preocupación por el tipo de mensaje y retórica que se trasladaba a la juventud era un sistemático motivo de preocupación en cada reportaje realizado a algún artista. Así, a León Gieco se le consultó por la responsabilidad que generaba el poseer una cierta influencia sobre la gente que consumía su arte lo que encontró como respuesta una reivindicación del esfuerzo necesario a realizar por el artista sobre el escenario 
y no una reflexión sobre el contenido ("León Gieco: Cantar las cosas" 3-5). A su vez, con frecuencia, se interrogó a los artistas sobre las características de la juventud en ese momento. Gieco, en sendas oportunidades, minimizó en sus respuestas cualquier tipo de referencia política sosteniendo que se trataba de un sujeto ávido de conocer pero que el rock no era un patrimonio necesariamente exclusivo de ella y, por su parte, Emilio del Guercio (entrevistado ante el regreso de Almendra en 1980 e interrogado por las diferencias con la juventud de años atrás) refirió exclusivamente al mal momento económico general en que se encontraba este sector ("Habla León Gieco" 20; "León Gieco: Cantar las cosas" 3-5; Winderbaum, "Almendra" 20-22). Con menos matices, en una entrevista a Lito Nebbia se le consultó los motivos por los cuales evitaba componer temáticas "de protesta" o "testimoniales" a lo que el compositor respondió que el arte tenía como fin la reflexión personal de quien lo recibía y no la realización de una práctica onanista en la que el público concurría a escuchar el mensaje con el que estaba de acuerdo sintiendo que así estaba logrando un cambio. A la vez, argumentó que la música con compromiso era también una forma de llegar a un público politizado y obtener un rédito de ello ("Lito Nebbia" 10-14).

Acorde a una revista juvenil de circulación en un contexto dictatorial, la represión al arte y, específicamente, el condicionamiento de aquello que se difundía, fue un tópico que sobrevoló, de un modo más o menos solapado. Esta preocupación se expresó en dos temáticas que aparecieron con frecuencia en Propuesta: el éxodo de artistas al exterior y la censura a las letras. El primero de estos temas surgió repetidamente en diversos reportajes interrogando a distintos artistas sobre las causas de su partida al exterior. Las respuestas solían recaer en evasivas y anclar la explicación en aspectos artísticos, como "la idea de equiparse para sonar mejor" ("Compartir" 13), económicos, como "buscar nuevos mercados" ("León Gieco: cantar" 3-5) o incluso personales, como "conocer otros lugares" ("Reportaje a Rodolfo García" 24-25).

El análisis de las letras y la censura también se vislumbró en Propuesta de diverso modo. Acorde a la idea del rock local como un campo de resistencia cultural al terrorismo de Estado, Pujol (Composición) sostuvo que la crítica política se mantuvo en estos años pero de una forma diferente ante un contexto que no permitía la realización de mensajes explícitos, teniendo el arte que utilizar una mayor sutileza semántica o metáforas que le permitieran sortear la censura. Esta vía de manifestación más soslayada no fue siempre interpretada como una respuesta contestataria a la represión. A modo de ejemplo, es ilustrativa la crítica de Propuesta ante la salida del primer álbum de Serú Girán. Ciertos análisis (Delgado) encontraron en este disco un modo poético 
de enfrentar a la censura y denunciar el contexto, no solo directamente (por ejemplo, a través de la canción "Autos, jets, aviones, barcos" que ofrecía una metáfora del exilio bastante elocuente) sino de modo encubierto. La letra de la canción "Serú Girán" supuso el uso de un idioma propio, inventado por la banda, lo que podría ser percibido como el modo más crudo de sortear la censura y denunciar la represión. Sin embargo, Propuesta criticó ese álbum como un producto carente de anclaje con la realidad que no presentaba perspectiva alguna de salida posible ("Discos" 26-27).

En distintos reportajes, el condicionante de la censura para la retórica del rock apareció de un modo indirecto, por ejemplo, interrogando a los artistas sobre las razones del cambio en las composiciones y el vacío en los mensajes. Ello generó respuestas incómodas que esbozaron su explicación en un cierto desinterés por las letras en beneficio de la música aunque, en oportunidades, apareció naturalmente como explicación el limitante de la censura comercial ("León Gieco: Cantar" 3-5; Correa, "Reportaje a Nito Mestre" 4-7). Con claridad, en un reportaje a Gieco, realizado a finales de 1979, se le consultó directamente cómo le afectaba la censura a lo que el cantante respondió que solo conocía la acción del COMFER (organismo encargado de regular la radio y televisión argentina) que le informaba qué canciones podían difundirse y cuáles no, pero que no tenía intención de intelectualizar sobre el significado de la censura en el país (Winderbaum, "León Gieco" 18-19).

Así como en La Chispa la temática predilecta al momento de analizar al rock local fue reflexionar sobre su politización y potencial radicalidad, en el caso de Propuesta, la preocupación central recayó en dilucidar si este fenómeno había ingresado en una senda comercial acorde a las necesidades del mercado y el consumo o, por el contrario, se trataba aún de un espacio contracultural para la juventud. Ya iniciada la dictadura cívico-militar, el rock local comenzó un proceso de extensión y ampliación de su público juvenil para dejar de ser, paulatinamente, un fenómeno sectorizado. Las fronteras antes instituidas entre el rock comercial y el rock alternativo (o progresivo) se diluyeron. Ello generó una mutación del género tanto a nivel comercial como político. En cuanto a lo primero, se produjo un incremento de los intereses de los productores y compañías discográficas que encontraron en el género un negocio rentable. Incluso, diversos músicos que habían partido al exterior con el golpe, retornaron paulatinamente al país incentivados comercialmente ante nuevos proyectos (Boix; Delgado). Pero, simultáneamente, los cambios internos que la propia dictadura esbozó, modificaron las concepciones y la actitud estatal que pesaban sobre el género. En efecto, entre 1979 y 1980, el 
rock se incorporó a la agenda del gobierno castrense iniciándose un período de confluencia entre productores, empresarios, músicos, funcionarios, audiencias y medios de comunicación, que alcanzó su momento de mayor fuste con festivales masivos como el show gratuito de Serú Girán en 1980, el Prima Rock en 1981 y el Festival de la Solidaridad Latinoamericana al año siguiente (Di Cione).

Ante este escenario, Propuesta se preguntaba cómo el rock debía manejar una masividad que se desarrollaba junto a un enorme aparato comercial, sin disolverse en él ni ponerse a su servicio. Sin renegar de los beneficios que la estructura empresarial brindaba al artista para ampliar la difusión de su arte, alertó sobre el vacío de contenido que ello traería aparejado (Correa, "Rock nacional" 18-21; "Rock: la chantada" 18-19). Desde esa lógica, la identificación de una crisis en el rock no era vista como producto de un cambio musical sino del contexto socio-cultural (Holcer 22-23). Bajo esta preocupación, la revista acudió a dos modos de intervención para enfrentar esa deriva comercial. Por un lado, destacó la supervivencia o aparición de bandas que se mantuvieron al margen de esta lógica. Por ejemplo, tuvo una importante ponderación la aparición del grupo MIA (Músicos Independientes Asociados), a quienes no se les reivindicaba tanto el resultado musical como su forma de organización basada en una lógica autogestiva en la que la propia banda producía sus recitales y discos, los difundía sin aparatos publicitarios y aquello recaudado se reinvertía en la renovación de sus instrumentos ("MIA" 34-35).

Por otro lado, fue frecuente una incisiva interpelación a los músicos en el momento de las entrevistas. Por ejemplo, en un reportaje conjunto a Raúl Porchetto y Nito Mestre se les consultó sobre la participación de músicos de rock en programas populares de la televisión, lo que fue defendido por los artistas bajo el argumento de ocupar un espacio disponible sin ceder en el contenido (Correa, "Reportaje" 4-7). Por su parte, se le preguntó a León Gieco por qué el rock dejó de encontrarse al margen de las pautas de consumo y a Moris, sin sutilezas, se le consultó si su estadía en Europa significó una adaptación al éxito alejándolo de sus anteriores intenciones honestas ("León Gieco: cantar" 3-5; "Moris: el inventor" 3-6). Como paroxismo de la interpelación al artista, se destaca un reportaje de Propuesta a Charly García de Daniel Otero y Oscar Zarco en el que la tensión se incrementó ante cada pregunta. El punto de partida fue un cuestionamiento de la revista al líder de Seru Girán por haber recomendado públicamente un equipo de música consultándole si "entró en el manejo". Luego, se lo cuestionó por una declaración realizada acerca de ser el primer artista en utilizar un bandoneón en un grupo de rock argentino (cuando en realidad ello no era así) interpelándolo sobre si ello no era un modo 
de vender el producto. Finalmente, ya en un clima de evidente tensión, los entrevistados juzgaron a García aseverando que pareciera haber "entrado en el juego". Este, a modo de defensa, respondió que:

Si querés muchos discos, querés trabajar y vivir de lo que hacés, tenés que entrar [al juego] porque sino terminás como cualquiera (...) teniendo que vender ventiladores para vivir. Y yo reamente no tengo ganas de trabajar en otra cosa que no sea la música. (...) Yo no vendo nada, yo simplemente hago música, y una compañía de discos agarra esa música y mete en un plástico negro y la vende. Es el mismo problema que tiene un oficinista que no le pagan y el patrón lo usa, yo no estoy fuera de la sociedad, los músicos de rock somos como el oficinista o el tipo que va a trabajar, tenemos las mismas trabas o las mismas cosas que no podemos decir (...) Pero yo creo que estoy para tocar para mucha gente, que mucha gente entiende lo que yo digo, entonces no me importan ciertos detalles así medio escrupulosos, como si el que maneja es un chanta y esas cosas. ("Habla García" 21)

Tras la alocución, la revista editorializó en el cierre de la nota aseverando tajantemente: "García, un joven músico, como se ve, despreocupado 'de ciertos detalles medio escrupulosos' y con un firme ideal: vivir de la música, es decir de nosotros consuetudinarios asistentes a recitales y consecuentes compradores de discos" ("Habla García" 21). Más allá de la crítica que la publicación manifestó en torno a la deriva comercial de los representantes del rock, resulta por demás interesante la contradicción planteada por el artista alrededor del músico como sujeto social. Charly García se autopercibió como un trabajador deseoso de que su labor no sea otra que el arte y, ante esa posibilidad, la necesidad de aceptar ciertos condicionamientos más allá de no ser los ideales. Resulta de interés que, para Propuesta, ello fue visto como sinónimo de claudicación y subordinación a las reglas del mercado sin identificar en la figura del músico un sujeto social trabajador que, como tal, aceptaba determinados condicionamientos y regimentaciones que le imponía la relación de fuerzas para poder desarrollar la actividad y sobrevivir.

El final de la revista obedeció a una decisión partidaria vertical a partir de un balance que, si bien destacó la calidad y difusión de la publicación, dio cuenta también de resultados negativos de acuerdo a sus objetivos iniciales. Tres aspectos eran vistos como limitantes para la continuidad de este proyecto. En primer lugar, la pérdida de una clara intervención partidaria en la línea 
política de la revista, lo que dio lugar, por momentos, a derivas discursivas frívolas, pasatistas e, incluso, machistas, en su contenido. En relación con ello, se percibió también una relativa autonomización del equipo partidario dedicado a esta tarea, lo que implicó, en la práctica, un cierto corrimiento con respecto a las directivas políticas partidarias generales y, por último, y centralmente, un balance negativo en cuanto a las finanzas, lo que dificultaba el sostenimiento de Propuesta sin un fuerte apoyo externo ("Balance y conclusiones"). Queda aquí en cierta evidencia las dificultades que provocaba para una organización partidaria la búsqueda de apertura de espacios más autónomos que, en sus intentos de aprovechamiento de los escasos márgenes de legalidad existentes, acababan por diluir su retórica y bagaje programático, lo que terminó por alertar y poner en cuestionamiento los propios objetivos iniciales del proyecto.

\section{CONCLUSIONES: ¿CAMINOS BIFURCADOS?}

El presente trabajo pretendió dar cuenta de los lazos y desencuentros entre dos actores coexistentes mediante la utilización de insumos documentales no explorados. El rock argentino y sus puentes con la militancia revolucionaria setentista encontraron, por lo general, un mayor interés por la indagación de aquellas visiones y nociones esgrimidas por las organizaciones político-militares (tanto marxistas como del campo de la izquierda peronista). En este artículo, el objetivo fue detenerse en una expresión menos explorada de las izquierdas, el trotskismo (puntualmente, el PST), a través de la indagación de dos publicaciones diversas, La Chispa y Propuesta, en dos momentos históricos con características bien diferenciables, los años de radicalización política post-Cordobazo y el contexto de la dictadura cívico-militar iniciada en 1976 con la puesta en práctica del terrorismo de Estado

Hace más de dos décadas, Alejandro Cataruzza propuso una agenda historiográfica para el estudio de los años setenta no circunscripta meramente al activismo de las organizaciones revolucionarias sino que recuperara aquella "cultura juvenil de masas" anclada a lo cultural que, en un contexto de álgida movilización social, también cuestionaba por otras vías al sistema imperante y a sus costumbres. Junto a este objetivo, aseveró la existencia de un conjunto de convicciones compartidas entre quienes participaban de la militancia política juvenil y aquellos que pensaban en un estilo de vida alternativo al urbano y consumista como, por ejemplo, las bandas de rock local y su público. Con matices frente a esta premisa, diversos estudios trazaron la posibilidad de 
una confluencia entre la militancia revolucionaria juvenil y el rock nacional como expresión contestataria. La aparición de este género como un rechazo al mundo adulto implicaba, desde ciertas perspectivas, la búsqueda de una alternativa a la industria cultural masiva (Díaz), o bien, una manifestación contra toda forma de opresión y violencia institucional (Alabarces). La ubicación del rock como respuesta al poder, al hallarse contextualizada en el ciclo de protestas que abrió el Cordobazo, permitió su identificación como una de las vertientes de la cultura juvenil contestataria y radicalizada de los años setenta (Manzano, La era).

En el presente artículo se sostuvo que, salvo en ciertos tópicos y en momentos particulares, se trató de dos campos alternativos y excluyentes que, indirectamente, disputaron la búsqueda de representación de la juventud. Como se esgrimió, en el caso de esta corriente, en el ciclo de ascenso político y radicalización de la Argentina de los años setenta, fue el momento de mayor confluencia y empatía entre ambas esferas. El repudio que desde el rock se realizaba a un gobierno dictatorial en decadencia como, así también, el rechazo a los valores occidentales y cristianos defendidos desde el propio Estado, fueron tópicos que le posibilitaron al trotskismo identificar en este género un canal de expresión relativamente cercano a sus intereses y factible de ser interpelado en miras de un proyecto revolucionario.

Sin embargo, el incremento de la violencia estatal y paraestatal experimentado en la Argentina hacia los años 1974 y 1975 que tuvo en las izquierdas un blanco privilegiado, modificó las líneas de análisis exigiendo a las expresiones culturales, como el rock, definiciones más concretas en torno a su ubicación política e ideológica en una disputa de clases que, se vislumbraba, cercana a su concreción. Ello llevó, en el caso del trotskismo, a alertar tajantemente en torno a las derivas comerciales y empresariales que el rock insinuaba, identificándolo como un movimiento cada vez más ajeno a la lucha emancipadora.

En diversos trabajos se sostuvo que la militancia de izquierda y la cultura del rock se desarrollaron por caminos bifurcados hasta que, finalmente, el golpe de Estado de 1976 terminó por unificarlos al transformarlos en un mismo blanco de la represión (Pujol, "Rebeldes"). Esta mirada conlleva un matiz de peso dado que, en primer lugar, los protagonistas del rock no tuvieron la pretensión de ocupar el espacio político que se hallaba perseguido sino, simplemente, erigirse como su representación cultural (Di Cione). En otro orden, sobre la base del análisis realizado a lo largo del trabajo, es factible concluir que, lejos de homogeneizarse, en estos años de represión exacerbada, la lógica de tratarse de dos campos diversos que se interpelaron y disputaron 
a la juventud, se mantuvo en ciernes. De hecho, el cuestionamiento por parte de esta corriente de izquierda a la ausencia de un mayor compromiso en las letras, la adopción de un cierto esnobismo y, sobre todo, la absorción del rock por parte del circuito comercial y empresarial, dieron como resultado la existencia de dos caminos antagónicos que acabaron por excluirse mutuamente. En definitiva, debió finalizar el proceso político más represivo de la historia argentina para que, en los posteriores años ochenta, ciertos sectores juveniles entendieran sin mayores contradicciones como acciones no necesariamente excluyentes la militancia al interior de un proyecto político radical y, simultáneamente, su ubicación como público o consumidor de este tipo de expresiones artísticas.

Agradezco a Leandro Molinaro las lecturas y sugerencias. Las opiniones que se desprenden del artículo son de exclusiva responsabilidad de su autor.

\section{REFERENCIAS BIBLIOGRÁFICAS}

Alabarces, Pablo. Entre gatos y violadores. El rock nacional en la cultura argentina. Colihue, 1993.

"Balance y conclusiones". Documento del PST, 1980.

Barr-Melej, Patrick. Psychedelic Chile: Youth, Counterculture, and Politics on the Road to Socialism and Dictatorship. University of North Carolina Press, 2017.

Beto Pelay de La Plata. "Rock". La Chispa, Año II, no. 16, Agosto de 1975, p. 28.

Boix, Ornela. "'Hubo un tiempo que fue hermoso": una relectura de la relación entre "rock nacional", mercado y política"”. Sociohistórica, no. 42, 2018. https://doi.org/10.24215/18521606e 060

Bufano, Sergio y Lucrecia Teixidó. Perón y la Triple A. Las 20 advertencias a Montoneros. Sudamericana, 2015.

Cataruzza, Alejandro. "El mundo por hacer. Una propuesta para el análisis de una cultura juvenil en la Argentina de los años setenta". Entrepasados, Año VI, no. 13, 1997, pp. 103-114.

Celiz, Hugo. "Pelo: ¿Sabés que no te entiendo?”. La Chispa, Año I, no. 10, 0411-1974. 
"Compartir las experiencias creativas: Miguel Cantilo, Kubero Díaz y La Cofradía de la Flor Solar”. Propuesta, Año II, no. 7, junio de 1978, p. 13.

Correa, Alejandro. "Reportaje a Nito Mestre y Raúl Porchetto: Lo que pasó y lo que se viene". Propuesta, Año II, no. 11, Noviembre de 1978, pp. 4-7.

-----. "Rock nacional: del ABC al Luna Park". Propuesta, Año II, no. 10, Octubre de 1978, pp. 18-21.

Delgado, Julián. “No se banca más”: Serú Girán y las transformaciones musicales del rock en la Argentina dictatorial"'. Revista Afuera: Estudios de Crítica Cultural, no. 15, 2015. http://www.historiapolitica.com/datos/ biblioteca/musica $\% 20 \mathrm{y} \% 20$ politica_delgado.pdf

Díaz, Claudio. Libro de viajes y extravios. Un recorrido por el Rock Argentino (1965-1985). Narvaja Editor, 2005.

Di Cione, Lisa. "Rock y dictadura en la Argentina: reflexiones sobre una relación contradictoria". Afuera. Revista de crítica cultural, no. 15, 2015. https:// www.academia.edu/35589044/Rock_y_dictadura_en_la_Argentina.

Reflexiones sobre una relaci\% $3 \% \mathrm{~B} 3 \mathrm{n}$ contradictoria

“Discos”. Propuesta, Año II, no. 12, Diciembre de 1978, pp. 26-27.

“Documento de orientación del Frente R. J.”. PST, 1979.

"Documento estudiantil", IV Congreso del PST, 15 y 16 de diciembre de 1973, p. 2.

"El rol de la JSA en la construcción del partido", Documento del II Congreso Extraordinario del PST, 28 y 29 de julio de 1973, p. 1.

"Entrevista a Silvio Winderbaum del autor". 21-07-2020, Neuquén, Argentina.

Favoretto, Mara. "La dictadura argentina y el rock: enemigos íntimos". Resonancias, vol. 18, no. 34, 2014, pp. 69-87. https://doi.org/10.7764/ res.2014.34.5

Franco, Marina. Un enemigo para la nación. Orden interno, violencia y 'subversión', 1973-1976. FCE, 2012.

Gerardo. "La radicalización del rock". La Chispa, Año I, no. 6, Agosto de 1974, pp. 10-11.

Goldman, Wendy. La mujer, el estado y la revolución. Política familiar y vida social soviéticas 1917-1936. IPS, 2010.

Grinberg, Miguel. "El éxodo y la pálida". Propuesta, Año II, no. 7, junio de 1978, pp. 6-8.

“Habla García”. Propuesta, Año II, no. 9, septiembre de 1979, p. 21. 
“Habla León Gieco". Propuesta, Año II, no. 9, septiembre de 1979, p. 20.

"Hijos vs. Padres". Avanzada Socialista, Año I, no. 26, 23-08-1972, p. 11.

Holcer, Ricardo. "Los grupos 'nuevos"”. Propuesta, Año II, no. 10, Octubre de 1978, pp. 22-23.

"La mujer comienza a liberarse". La Verdad, no. 278, 25-08-1971, p. 4.

" "La ley de los anticonceptivos es una medida más de tipo represivo" nos dijo Cipe Linkovsky". Avanzada Socialista, Año 2, no. 97, del 28 de marzo al 5 de abril de 1974, p. 4.

"León Gieco: Cantar las cosas del que cantar no quiere". Propuesta, Año II, no. 13, enero de 1979, pp. 3-5.

"León Gieco: época de hacer y saber". La Chispa, Año II, no. 15, Mayo de 1975, p. 23.

"Lito Nebbia: Algo más que un vendedor de promesas". Propuesta, Año II, no. 14, marzo de 1979, pp. 10-14.

Mangiantini, Martín. Itinerarios militantes. Del Partido Revolucionario de los Trabajadores al Partido Socialista de los Trabajadores (1965-1976). Imago Mundi, 2018.

-----. "Nociones y tensiones de una cultura revolucionaria. Entre la militancia juvenil, la proletarización y la preocupación por las derivas pequeño-burguesas". Prácticas de oficio. Investigación y reflexión en Ciencias Sociales. (IDES), volumen 2, no. 22, 2019, pp. 67-77. https://static.ides.org.ar/archivo/ www/2019/03/7-MANGIANTINI.pdf

Mangiantini, Martín y Catalina Trebisacce. "Feminismo, diversidad sexual y relaciones sexo-afectivas disidentes. Apuestas y tensiones en el Partido Socialista de los Trabajadores (PST) entre 1971 y 1975". Revista Archivos de Historia del Movimiento Obrero y la Izquierda, año 4, no. 7, 2015, pp. 101-120. https://doi.org/10.46688/ahmoi.n7.137

Manzano, Valeria. La era de la juventud en Argentina. Cultura, politica y sexualidad desde Perón hasta Videla. Fondo de Cultura Económica, 2017.

-----. "Política, cultura y el "problema de las drogas" en la Argentina, 19601980s". Apuntes de investigación del CECYP, Año XVII, no. 24, 2014, pp. 51-78. http://www.apuntescecyp.com.ar/index.php/apuntes/article/ view/472

Marcelo. “¿Por qué se drogan los jóvenes?”. La Chispa. Año I, no. 7, Septiembre de 1974, pp. 10-11. 
Markarian, Vania. El 68 uruguayo: El movimiento estudiantil entre molotovs y música beat. UNQUI, 2012.

"Más hijos ¿Quién los alimenta? No al decreto contra los anticonceptivos". Avanzada Socialista, Año 2, no. 96, del 20 al 27 de marzo de 1974, p. 6.

"MIA: después del ciclo". Propuesta, Año II, no. 13, enero de 1979, pp. 34-35.

"Moris: el inventor de ciudades". Propuesta, Año III, no. 18, julio de 1979, pp. 3-6.

"Moris: pionero del rock". La Chispa, Año I, no. 6, Agosto de 1974, p. 11.

"Mujeres en lucha", Avanzada Socialista, Año 1, no. 3, 15-03-1972, p. 10.

Pozzi, Pablo. Por las sendas argentinas. El PRT-ERP, la guerrilla marxista. Imago Mundi, 2004.

Pujol, Sergio. Composición libre: la creación musical en la Argentina en democracia. Editorial de la Universidad Nacional de La Plata, 2015.

-----. "Rebeldes y modernos. Una cultura de los jóvenes". Violencia, proscripción y autoritarismo, compilado por Daniel James, Sudamericana, 2003, pp. 281-328.

-----. Rock y dictadura. Crónica de una generación 1976-1983, compilador en: Daniel James, Emecé, 2005.

"Reportaje a Rodolfo García y Héctor Starc: Después de Aquelarre". Propuesta, Año II, no. 12, Diciembre de 1978, pp. 24-25.

"Reportaje a Sui Generis: Un rock que ayude a la revolución". La Chispa, Año I, no. 8, 23-09-1974, pp. 14-15.

"Rock en derecho". La Chispa. Año I, no. 7, Septiembre de 1974, p. 13.

"Rock: la chantada comercial". Propuesta, Año II, no. 9, septiembre de 1979, pp. 18-19.

“Sexo: ¿tabú o liberación?”. La Chispa, Año I, no. 9, 14-10-1974, pp. 14-15.

Simonetto, Patricio. Entre la injuria y la revolución. El Frente de Liberación Homosexual. Argentina, 1967-1976. Universidad Nacional de Quilmes, 2017.

“Una JS autónoma". La Chispa. Órgano de la JSA. Año I, no. 6, Septiembre de 1974, p. 12.

Vila, Pablo. "Rock nacional: crónicas de la resistencia juvenil". Los nuevos movimientos sociales: mujeres, rock nacional, compilado por Elizabeth Jelin, Centro Editor de América Latina, 1985, pp. 83-158.

-----. “Argentina's 'Rock Nacional': The Struggle for Meaning”. Latin American Music Review, vol. 10, no.1, 1989, pp. 1-28. https://doi. org/10.2307/780380 
Winderbaum, Silvio. "León Gieco". Propuesta, Año III, no. 21, noviembre de 1979, pp. 18-19.

-----. "Vuelve el rock nacional". Propuesta, Año III, no. 20, octubre de 1979, pp. 24-25.

-----. “Almendra: 'Reorganizar la energía dispersa'”. Propuesta, Año III, no. 21, noviembre de 1979, pp. 20-22.

Zolov, Eric. Refried Elvis: The Rise of the Mexican Counterculture. University of California Press, 1999. https://doi.org/10.1525/9780520921504 